\title{
PENGARUH KUALITAS JASA PERSPEKTIF ISLAM TERHADAP KEPUASAN DAN LOYALITAS PELANGGAN HOTEL GRAND KALIMAS DI SURABAYA ${ }^{1)}$
}

\author{
Fitria Solahika Salma \\ Mahasiswa Program Studi S1 Ekonomi Islam-Fakultas Ekonomi dan Bisnis-Universitas Airlangga \\ Email: fitriasolahikasalma@yahoo.com \\ Ririn Tri Ratnasari \\ Dosen Departemen Ekonomi Syariah-Fakultas Ekonomi dan Bisnis-Universitas Airlangga \\ Email: riratnasari@gmail.com
}

\begin{abstract}
:
This study intends to know the influences of service quality perspective Islamic on the satisfication and the customer loyalty of Grand Hotel Kalimas in Surabaya. In achieving the aim, this study uses quantitative approach particularly in path analysis. Questioner is used in this study as primary data source of this study, moreover the data sampling of this study taken from 30 respondents. Meanwhile, method of data collection uses probability sampling with accidental sampling approach.

For the results, the writer finds that the quality of perspective Islamic gives significant impact toward the satisfication of the customer, but it does not give significant impact toward the loyalty of customer. However, the satisfication of the customer gives significant influence toward the loyalty of the customer, Islamic perspective of service quality indirect effect on customer loyalty.

Keywords: service quality of perspective Islamic, satisfication of customer, loyalty of customer, and sharia hotel.
\end{abstract}

\section{PENDAHULUAN}

Pariwisata dalam Islam disebut dengan rihlah yang bermakna berpindah dari suatu tempat ke tempat lainnya untuk mencapai suatu tujuan materi atau immateri. Rihlah atau suatu perjalanan yang sangat dianjurkan, terutama rihlah yang mengandung nilai-nilai ibadah (AshSha'idi 1998: 17 dalam Kholidah 2014: 1-2).

Hal ini didukung dengan Indonesia merupakan negara dengan mayoritas penduduk beragama Islam, sebanyak $88,2 \%$ dari total penduduk Indonesia beragama Islam dan sebanyak $12,9 \%$ dari total Muslim di dunia, dengan jumlah mencapai 202,9 juta orang (Jafari dan Scott 2013). Adapun langkah konkrit dalam usaha mengembangkan pariwisata syariah adalah dengan merancang produk dan daerah tujuan pariwisata syariah. (indonesia-travel.com). Jawa Timur merupakan salah satu daerah yang potensial sebagai tujuan wisata syariah. Hal tersebut dikarenakan di Jawa Timur terdapat makam lima sunan (Wali Songo). Salah satu tempat wisata yang banyak dikunjungi oleh wisatawan Muslim adalah Masjid Sunan Ampel Surabaya. Menurut Dinas Kebudayaan dan Pariwisata Provinsi Jatim melalui Warta Metropolis Jatim (2014) jumlah pengunjung Sunan Ampel Surabaya sebanyak 1.768.661 per tahun.

Hotel syariah merupakan bagian yang tidak dapat dipisahkan dari kegiatan wisata syariah. Namun seiring meningkatnya jumlah wisatawan Muslim,

1] Jurnal ini merupakan bagian dari skripsi Fitria Solahika Salma, NIM: 041014071, yang diuji pada 13 Februari 2015 
tidak diimbangi dengan berkembangnya hotel syariah. Menurut Soleh selaku Ketua Perhimpunan Hotel dan Restoran Indonesia (PHRI) BPD Jawa Timur dalam Jawa Pos (2015) bahwa hotel syariah khususnya di Jawa Timur kurang berkembang, hal ini dikarenakan hotel syariah identik dengan fasilitas yang kotor dan tidak memuaskan. Menurut Anshori (2010: 2) hotel merupakan salah satu industri jasa dibidang penginapan yang sangat bergantung sekali kepada kualitas jasa yang disediakan dalam melayani pelanggan.

Penelitian tentang kualitas jasa dan pengukurannya pertama kali dilakukan oleh Parasuraman et al. (1985) dimana merumuskan model service Quality (SERVQUAL) yang di dalamnya terdapat lima dimensi yakni Tangibles (penampilan fasilitas fisik, peralatan, personil, dan materi komunikasi), Reliability (kemampuan untuk melakukan kualitas jasa yang menjanjikan kehandalan dan keakuratan), Responsiveness (kemauan untuk membantu pelanggan dan memberikan jasa dengan cepat), Assurance (pengetahuan, kesopanan dan kemampuan yang dimiliki karyawan untuk menginspirasi kepercayaan dan keyakinan), Empathy (perhatian individual yang diberikan kepada pelanggan).

Islam merupakan agama yang mengatur segala dimensi kehidupan. AlQur'an diturunkan Allah SWT kepada manusia untuk memberikan solusi atas segala permasalahan hidup. Oleh karena itu, setiap aktivitas hidup terkait dalam aturan syariah. Demikian halnya dalam penyampaian jasa, setiap aktivitas yang terkait harus didasari oleh kepatuhan terhadap syariah yang penuh dengan nilai-nilai moral dan etika. Perkembangan organisasi jasa syariah telah memberikan dimensi baru dalam pengukuran kualitas jasa (Ratnasari et al. 2012).

Othman dan Owen (2001) mengembangkan pengukuran kualitas jasa dalam perspektif Islam. Dalam jurnalnya yang berjudul Adopting and Measuring Customer Service Quality (SQ) in Islamic Banks: A Case Study In Kuwait Finance House mereka menambahkan dimensi Compliance (kepatuhan) dalam SERVQUAL Parasuraman (Assurance, Responsiveness, Tangibles, Empathy, dan Reability) yang kemudian disebut dengan CARTER (Compliance, Assurance, Responsiveness, Tangibles, Empathy, dan Reability). Rehman (2012) menjelaskan bahwa metode ini menggunakan lima dimensi yang terdapat dalam SERVQUAL (Tangible, Responsiveness, Reliability, Assurance, Empathy) dan menambahkan dimensi Compliance (kepatuhan terhadap syariah Islam) di dalamnya. Othman dan Owen (2001) menempatkan Compliance sebagai landasan utama dalam mengukur kualitas jasa.

Berdasarkan seluruh proses kegiatan pemberian kualitas jasa oleh perusahaan, pada akhirnya akan berakhir dengan kepuasan pelanggan (Ratnasari dan Aksa 2011:117). Menurut Lovelock dan Wright (2007: 96) kualitas jasa adalah evaluasi 
kognitif jangka panjang pelanggan terhadap penyerahan jasa. Kualitas jasa yang diberikan secara baik oleh suatu perusahaan jasa akan memiliki pengaruh positif terhadap kepuasan pelanggan.

Kualitas jasa sangat penting dalam mempertahankan pelanggan dalam waktu yang lama (Gilbert et al. 2004). Kepuasan pelanggan akan dicapai dengan kualitas jasa yang tinggi dan perilaku kualitas jasa yang baik akan menghasilkan pengurangan penurunan pelanggan (Leeds 1992 dalam Rehman 2012: 167). Lovelock dan Wright (2007: 104) mengatakan bahwa kepuasan pelanggan akan memberikan banyak manfaat bagi perusahaan dan tingkat kepuasan pelanggan yang semakin tinggi akan menghasilkan loyalitas pelanggan yang lebih besar, sehingga dalam jangka panjang akan lebih menguntungkan dalam hal mempertahankan pelanggan jika dibandingkan dengan usaha terus menerus menarik dan membina pelanggan baru untuk menggantikan pelanggan yang pergi. Apabila jasa yang diberikan tidak sesuai harapan, maka pelanggan akan kecewa dan dapat berpindah ke produk jasa pesaing. Sebaliknya, apabila pelangga puas maka mereka lebih cenderung untuk loyal terhadap jasa. Pelanggan yang sangat puas akan menyebarkan cerita positif dari mulut ke mulut dan menjadi iklan berjalan bagi suatu perusahaan.

Oleh karena itu pengelola hotel syariah harus segera mulai memperbaiki kualitas jasa yang diberikan kepada pelanggannya karena faktor ini yang akan menentukan daya tarik masyarakat untuk memilih hotel syariah sebagai tempat penginap ketika bepergian. Melalui kualitas jasa yang tinggi dan memiliki moral dalam bidang pariwisata serta wujud tanggungjawab kepada stakeholder dan lingkungan, sehingga manajemen hotel syariah harus memiliki komitmen untuk memberikan kualitas jasa secara terus-menerus untuk peningkatan kepuasan dan menciptakan loyalitas pelanggannya.

Berdasarkan uraian latar belakang di atas, maka penelitian ini dilakukan di hotel syariah di Surabaya. Hotel syariah yang dipilih sebagai objek penelitian adalah hotel Grand Kalimas Surabaya. Hotel Grand Kalimas Surabaya telah mengukuhkan diri sebagai pioner hotel berkonsep syariah di Surabaya, menyusul telah diterimanya sertifikasi syariah dari Majelis Ulama Indonesia (MUI) Surabaya. Konsep syariah pada Hotel Grand Kalimas Surabaya sengaja diterapkan selain didasari oleh keinginan untuk memberikan kenyamanan dan keamanan serta kualitas jasa terbaik bagi pelanggan, yang notabene sebagian besar adalah pengunjung di wisata religi Sunan Ampel Surabaya (kabarbisnis.com 2013).

\section{Rumusan Masalah Penelitian}

1. Apakah kualitas jasa perspektif Islam berpengaruh terhadap kepuasan pelanggan hotel Grand Kalimas di Surabaya?

2. Apakah kualitas jasa perspektif Islam berpengaruh terhadap loyalitas 
pelanggan hotel Grand Kalimas di Surabaya?

3. Apakah kepuasan pelanggan berpengaruh terhadap loyalitas pelanggan hotel Grand Kalimas di Surabaya?

\section{Tujuan Penelitian}

1. Mengetahui pengaruh kualitas jasa perspektif Islam berpengaruh terhadap kepuasan pelanggan hotel Grand Kalimas di Surabaya.

2. Mengetahui pengaruh kualitas jasa perspektif Islam berpengaruh terhadap loyalitas pelanggan hotel Grand Kalimas di Surabaya.

3. Mengetahui pengaruh kepuasan pelanggan terhadap loyalitas pelanggan hotel Grand Kalimas di Surabaya.

\section{LANDASAN TEORI}

Hotel syariah adalah salah satu model hotel yang menawarkan fasilitas yang sesuai dengan nilai Islam, sehingga mampu meminimalisir adanya praktek perzinahan, minuman keras, pshycotropika, perjudian. Apabila hotel tegas dalam memberlakukan syaratsyarat tamu pengunjung, maka masyarakat juga akan berpikir ulang untuk melakukan yang melanggar pidana (Sabri 2010: 118). Kebolehan bisnis perhotelan didasarkan pada firman Allah SWT, yakni dalam surat An-Nur [24] ayat 29:

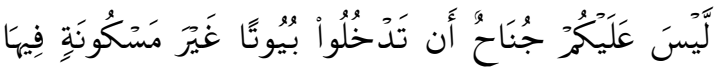

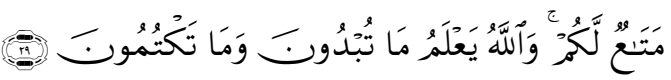

Laisa 'alaikum junāhun antad khulū buyūtan gaira maskūnatin fîhā matā'ullakum, wal lāhu ya'lamu mātubdūna wamā taktumūn(a).

"Tidak ada dosa atasmu memasuki rumah yang tidak dihuni, yang di dalamnya ada kepentingan kamu, dan Allah mengetahui apa yang kamu nyatakan dan apa yang kamu sembunyikan". (Departemen Agama Rl, 2010)

Imam Thabari dalam (Hayati 2014) menafsirkan ayat tersebut dengan "Tidak ada dosa atasmu untuk memasuki rumahrumah yang tidak berpenghuni tanpa izin". Mengenai rumah apa yang di maksud, para ulama berbeda pendapat. Sebagian berpendapat bahwa rumah yang dimaksud adalah hotel dan rumahrumah yang dibangun di perjalanan dan tidak memiliki penghuni yang tertentu. Rumah-rumah tersebut dibangun untuk para pelancong dan orang-orang yang dalam perjalanan agar mereka menginap dan menempatkan barang-barang mereka disitu" (Jami' al Bayan fi Ta'wil al Quran, Thabari 19/151).

\section{Kualitas Jasa Perspektif Islam}

Dimensi kualitas jasa perspektif Islam pertama kali diperkenalkan oleh Othman dan Owen (2011) yang digunakan untuk mengukur kualitas jasa. Dimensi tersebut adalah CARTER model, yaitu Compliance, Assurance, Reliability, Tangible, Empathy dan Responsiveness (CARTER).

Dimensi CARTER yang dijelaskan dalam konsep Islam adalah sebagai berikut (Ratnasari et al. 2012):

1. Compliance (kepatuhan)

Compliance adalah kepatuhan terhadap aturan atau hukum-hukum yang 
ditetapkan dalam Al-Qur'an dan AsSunnah (syariah). Ratnasari et al. (2012) mengatakan bahwa syariah Islam merupakan pedoman sekaligus aturan yang diturunkan Allah SWT untuk diamalkan oleh para pemeluknya dalam setiap kehidupan agar tercipta keharmonisan dan kebahagian. Pengetahuan seseorang tentang syariah akan meningkatkan kepatuhannya terhadap perintah dan larangan Allah SWT, sehingga memunculkan kepribadian yang penuh moral dan etika. Keyakinan terhadap Allah SWT akan memberikan stabilitas emosi pada individu dan motivasi positif dalam setiap aktifitas bisnisnya.

\section{Assurance (jaminan)}

Pengetahuan dan kemahiran atas suatu produk hanya akan diperoleh dari sebuah proses belajar yang tekun dan bersungguh-sungguh. Islam memerintahkan agar setiap muslim senantiasa belajar dengan tekun dan terus meningkatkan kemampuan dirinya. Peningkatan pengetahuan personal sangatlah penting bagi organisasi jasa. Karyawan yang memiliki pengetahuan luas terhadap jasa, akan mampu berbicara lebih luas tentang jasa tersebut dan dapat menyampaikan jasa lebih baik kepada pelanggan. Hal ini didasarkan firman Allah SWT tentang keutamaan orang yang berilmu.

Bagian lain dari dimensi assurance adalah sikap karyawan yang ramah dan sopan. Hal tersebut dapat menarik perhatian dan membentuk hubungan baik antara kedua belah pihak. Sikap tersebut merupakan bagian dari etika perdagangan yang harus dijalankan oleh setiap muslim. Allah SWT juga memerintahkan kepada muslim untuk mengucapkan kata-kata yang baik ketika berinteraksi dengan orang lain. Perkataan yang baik (sopan) dan lemah lembut (ramah) akan membentuk pola interaksi yang berkualitas.

3. Responsiveness (daya tanggap)

Daya tanggap merupakan bagian dari profesionalitas. Organisasi yang profesional senantiasa berkomitmen untuk memberikan pelayanan terbaik, memperhatikan harapan dan masukan dari pelanggan serta meresponnya dengan cepat dan tepat. Jika tidak demikian, berarti manajemen organisasi tersebut telah menzalimi pelanggan. Allah SWT melarang setiap muslim untuk berbuat zalim dalam berserikat/berbisnis.

4. Tangible (bukti fisik)

Bukti fisik merupakan tampilan fisik yang akan menunjukkan identitas organisasi sekaligus faktor pendorong munculnya persepsi awal pelanggan terhadap suatu organisasi jasa. Ketidakmampuan organisasi dalam menampilkan bukti fisiknya dengan baik, akan melemahkan citra serta dapat menciptakan persepsi negatif pada pelanggan. Dimensi lain dalam tangible adalah bukti fisik personal, yakni karyawan dalam berpenampilan atau berpakaian. Dalam syariah Islam, diwajibkan untuk menutup aurat.

5. Empathy (empati) 
Sebuah organisasi jasa syariah harus senantiasa memberikan perhatian khusus terhadap masing-masing pelanggannya yang ditunjukkan dengan sikap komunikatif yang diiringi kepahaman tentang kebutuhan pelanggan. Hal ini merupakan wujud kepatuhan penyedia jasa terhadap perintah Allah SWT untuk selalu peduli terhadap kondisi dan kebutuhan orang lain

\section{Reliability (kehandalan)}

Pelayanan akan dapat dikatakan reliabel apabila dalam perjanjian yang telah diungkapkan dicapai secara akurat. Ketepatan dan keakuratan inilah yang akan menumbuhkan kepercayaan konsumen terhadap lembaga penyedia layanan jasa. Dalam konteks ini, Allah SWT juga menghendaki setiap umat-Nya untuk menepati janji yang telah dibuat

\section{Kepuasan Pelanggan Dalam Islam}

Dalam ilmu ekonomi Islam, kepuasan seorang muslim disebut dengan qana'ah. Kepuasan dalam Islam (qana'ah) merupakan cerminan kepuasan seseorang baik secara lahiriah maupun batiniyah. Kepuasan dalam Islam mendorong seorang konsumen Muslim bersikap adil. (Muflih, 2006: 87). Konsep kepuasan dalam Islam berkaitan dengan keimanan yang melahirkan rasa syukur (Zulfa, 2010: 192).

Kepuasan menurut Islam harus mempertimbangkan beberapa hal berikut (Muflih, 2006: 12):

1. Barang atau jasa yang dikonsumsi harus halal
2. Dalam mengkonsumsi barang atau jasa tidak berlebih-lebihan

3. Tidak mengandung riba

\section{Loyalitas Pelanggan Dalam Islam}

Loyalitas dalam Islam disebut dengan al-wala'. Secara etimologi, alwala' memiliki beberapa makna, antara lain mencintai, menolong, mengikuti, dan mendekat kepada sesuatu. (Dakwatuna.com 2014). Konsep loyalitas dalam Islam atau al-wala' adalah ketundukan mutlak kepada Allah SWT dalam wujud menjalankan syariah Islam sepenuhnya (Zulfa, 2010: 192). Loyalitas pelanggan dalam Islam terjadi apabila aktivitas muamalah itu dapat memberi manfaat yang saling menguntungkan kedua belah pihak, karena terpenuhinya kewajiban serta hak masing-masing melalui penerapan nilai-nilai Islam (Zulfa, 2010: 187).

\section{Hipotesis}

Kualitas jasa berfokus pada upaya pemenuhan kebutuhan dan keinginan pelanggan, serta ketepatan penyampaiannya untuk mengimbangi harapan pelanggan (Tjiptono 2005: 259). Jika kualitas jasa berada di bawah harapan, pelanggan tidak puas. Jika kualitas jasa memenuhi harapan, pelanggan puas. Jika kualitas jasa melebihi harapan, pelanggan amat puas atau senang (Kotler dan Keller 2009: 138139). Salah satu faktor penentu tingkat kepuasan pelanggan dalam industri jasa adalah kualitas jasa. 
Dalam perspektif Islam, memberikan jasa haruslah mendasarkan pada nila-nilai Islam guna mewujudkan nilai ketakwaan sekaligus membuktikan konsistensi keimanannya dalam rangka menjalankan misi syariat Islam. Tentunya hal tersebut dilakukan tidaklah hanya berorientasi pada komitmen semata, namun sebagai bagian dari nilai ibadah. Dalam pandangan Islam yang dijadikan tolak ukur untuk menilai kualitas jasa terhadap pelanggan yaitu standarisasi syariah (Rahmawati 2014: 62). Berdasarkan penjelasan tersebut hipotesis yang akan divji adalah:

$\mathrm{H1}$ : Pengaruh kualitas jasa perspektif Islam terhadap kepuasan pelanggan hotel Grand Kalimas di Surabaya.

Islam berupaya menjauhkan umatnya dari perilaku yang hanya mementingkan diri sendiri seraya mengabaikan kepentingan orang lain ( Ryandono, 2009: 22). Nabi Muhammad SAW benar-benar menghargai pelanggannya sebagaimana Nabi Muhammad SAW menghargai dirinya sendiri. Hal ini merupakan cara paling efektif dalam mempertahankan pelanggan sehingga yang terjadi adalah hubungan yang sangat baik antara pengusaha dengan pelanggan, dan pada akhirnya loyalitas pelanggan akan terbentuk dengan sendirinya. Nabi Muhammad SAW tidak hanya memandang service diperlukan hanya pada saat menjual tetapi juga pada saat membeli Gunara dan Sudibyo (2007: 88).
Putra (2014) menyatakan bahwa anjuran Islam yang mengajarkan bahwa penyedia jasa harus memberikan kualitas jasa yang baik bagi pelanggan, agar pelanggan tetap setia menggunakan jasanya. Islam menganjurkan untuk menjaga hubungan dengan berbagai golongan dengan memberikan kualitas jasa yang baik. Penyedia jasa memberikan kualitas jasa yang baik dengan menjaga hubungan baik dengan pelanggannya agar tercipta hubungan jangka panjang yang baik dan membentuk loyalitas pelanggan. Berdasarkan penjelasan tersebut maka hipotesis yang akan diuji adalah

H2: Pengaruh kualitas jasa perspektif Islam terhadap loyalitas pelanggan hotel Grand Kalimas di Surabaya Muflih (2006: 88) mengatakan bahwa kepuasan pelanggan dalam Islam berarti menerima dengan ikhlas kondisi yang dialami, baik itu dalam keadaan kaya dan miskin. Kepuasan pelanggan dalam Islam mendorong pelanggan untuk bersikap adil dan mencapai keseimbangan hidupnya. Menurut Ratnasari (2011) keseimbangan dalam hidup akan menciptakan jiwa yang memiliki loyalitas yang merasakan ketenangan lahir dan batin yang luar biasa. Jiwa loyalitas mencerminkan sikap konsisten dan teguh pendirian untuk menggunakan sebuah jasa agar pelanggan menuju keadaan yang lebih baik. Loyalitas pelanggan dalam Islam akan kokoh kalau dibangun dari kepuasan Islam (Zulfa, 2010). Berdasarkan 
penjelasan tersebut maka hipotesis yang akan divji adalah

H3: Pengaruh kepuasan pelanggan terhadap loyalitas pelanggan hotel Grand Kalimas di Surabaya

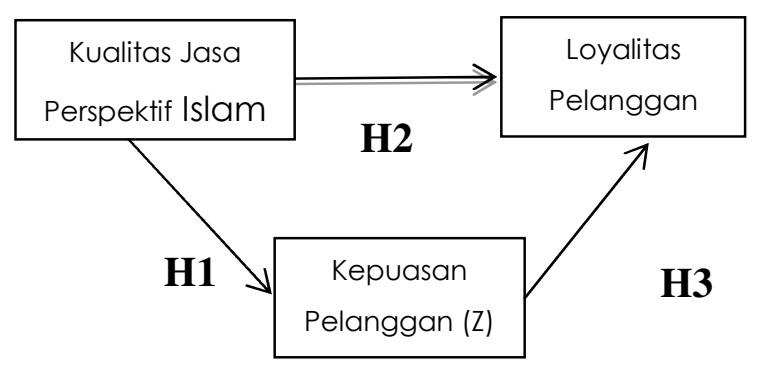

Sumber: penulis

Gambar 1.

\section{METODE PENELITIAN}

\section{Kerangka Teoritis}

Pendekatan dalam penelitian ini menggunakan pendekatan kuantitatif. Penelitian ini bertujuan untuk menganalisis dan membuktikan adanya pengaruh variabel eksogen terhadap endogen melalui variabel endogen intervening.

Variabel eksogen adalah variabel yang mempengaruhi variabel lain dalam penelitian sehingga variabel ini dikenal pula dengan variabel bebas (independent variable) (Sanusi 2011: 52). Variabel eksogen $(X)$ pada penelitian ini adalah Kualitas Jasa Perspektif Islam (X). Variabel endogen merupakan variabel yang dipengaruhi oleh variabel lain dalam suatu penelitian, oleh karena itu variabel endogen sebenarnya sama dengan variabel terikat (Sanusi 2011: 52). Variabel endogen ( $Y$ ) pada penelitian ini adalah Kepuasan Pelanggan (Z). Variabel intervening adalah variabel yang secara teoritis mempengaruhi hubungan antara variabel independen dengan dependen menjadi hubungan yang tidak langsung dan tidak dapat diamati dan diukur (Sugiyono 2011: 39). Variabel intervening (Z) pada penelitian ini adalah Loyalitas Pelanggan $(Y)$.

\section{Populasi}

Populasi dalam penelitian ini adalah pengunjung yang penginap di Hotel Grand Kalimas Surabaya selama bulan Januari 2015. Teknik yang digunakan untuk pengambilan sample adalah nonprobability sampling dengan pendekatan accidental sampling. Yang dimaksud dengan accidental sampling adalah metode dengan cara pengambilan sampel secara kebetulan. Anggota populasi yang secara kebetulan dijumpai oleh peneliti pada saat penelitian, maka itulah menjadi sampelnya (Masyhuri dan Zainuddin 2009: 178).

\section{Definisi Operasional}

Definisi operasional dalam penelitian ini adalah:

1. Kualitas jasa perspektif Islam (Compliance, Assurance, Responsiveness, Tangibles, Empathy, dan Reability). Hotel Grand Kalimas adalah hotel syariah di Surabaya yang pertama kali mendapatkan sertifikat dari MUI; Hotel Grand Kalimas melarang pasangan yang bukan mahram menginap dalam satu kamar; hotel Grand Kalimas menyediakan makanan dan minuman yang halal; karyawan hotel Grand Kalimas memberikan pelayanan yang sopan dan ramah; tamu hotel Grand Kalimas merasa aman saat berinteraksi dan bertransaksi 
dengan karyawan hotel; karyawan hotel Grand Kalimas (beel boy, room attendant, waiter) memberi pelayanan yang diminta tamu dengan segera; karyawan hotel Grand Kalimas bersedia membantu tamu hotel; fasilitas di dalam kamar hotel Grand Kalimas terdapat petunjuk arah kiblat, tasbih, Al Qur'an, sajadah, dan channel live dari Timur Tengah; fasilitas di kamar mandi hotel Grand Kalimas, closet tidak menghadap atau membelakangi kiblat serta terdapat kran air untuk berwudhu; mushalla di hotel Grand Kalimas bersih, tidak lembab, dan mukena yang bersih; seragam karyawan hotel Grand Kalimas sesuai dengan kaidah berpakaian dalam Islam yaitu menutup aurat; karyawan hotel Grand Kalimas segera meminta maaf kepada tamu saat terjadi kesalahan dalam memberikan pelayanan; setiap berinterkasi dengan tamu, karyawan hotel Grand Kalimas memanggil dengan nama tamu; karyawan hotel Grand Kalimas (front-desk) tidak melakukan kesalahan dalam memberikan pelayanan; karyawan hotel Grand Kalimas memberikan pelayanan kepada tamu sesuai dengan waktu yang dijanjikan; waktu pelayanan pada saat check-in cepat.

2. Kepuasan pelanggan. Pelanggan hotel Grand Kalimas memiliki rasa syukur terdapat hotel Grand Kalimas di Surabaya; pelayanan hotel Grand Kalimas sesuai dengan harapan pelanggan; pelanggan merasa pelayanan hotel Grand Kalimas sesuai dengan yang dijanjikan; manfaat yang pelanggan rasakan saat menginap di hotel Grand
Kalimas sesuai dengan biaya yang pelanggan keluarkan; pelanggan puas dengan pengalaman menginap di hotel Grand Kalimas

3. Loyalitas pelanggan. Pelanggan merekomendasikan hotel Syariah Grand Kalimas kepada orang lain; saat pelanggan berkunjung kembali ke hotel Grand Kalimas, pelanggan akan menginap di kamar yang memiliki standart lebih tinggi; ketika hotel Grand Kalimas mengalami kenaikan harga, pelanggan akan tetap menginap di hotel Grand Kalimas; pelanggan akan menginap kembali di hotel Syariah Grand Kalimas jika berkunjung ke Surabaya; pelanggan memberitahu kepada orang lain bahwa hotel Grand Kalimas lebih layak, bagi yang menghendaki hotel syariah; pelanggan memberitahu kepada orang lain tentang keuntungan menginap dengan fasilitas di hotel Grand Kalimas; pelanggan memberitahu kepada orang Iain bahwa hotel Grand Kalimas memiliki pelayanan yang memuaskan.

\section{Teknik Analisis}

Teknik analisis data dalam penelitian ini menggunakan analisis jalur (path analysis). Penelitian ini menggunakan persamaann struktural untuk variabel endogen intervening (Z) adalah (Solimun 2002: 97):

$$
\mathrm{Z}=\gamma \mathrm{X}+e
$$

$\mathrm{Z} \quad=$ Kepuasan pelanggan hotel Grand Kalimas Surabaya

$\gamma=$ Koefisien jalur dari variabel eksogen ke variabel endogen

$\mathrm{X}=$ Kualitas jasa perspektif Islam 
e $\quad=$ Standart error

Penelitian ini menggunakan persamaan struktural untuk variabel endogen (Y) adalah (Solimun 2002: 97):

$$
\mathrm{Y}=\beta \mathrm{Z}+\gamma \mathrm{X}+e
$$

$\mathrm{Y}=$ Loyalitas Pelanggan hotel Grand Kalimas Surabaya

Z = Kepuasan Pelanggan hotel Grand Kalimas Surabaya

$\gamma=$ Koefisien jalur dari variabel eksogen ke variabel endogen

$\beta=$ Koefisien jalur dari variabel endogen ke variabel endogen

$\mathrm{X} \quad=$ Kualitas jasa perspektif Islam

e $\quad=$ Standart error

\section{HASIL DAN PEMBAHASAN}

Uji outlier terdiri dari outlier univariate dan multivariate. Outlier univariate dilakukan dengan mengamati nilai Z score yang diolah dengan menggunakan program SPSS. Data dikatakan tidak terjadi outlier jika mempunyai nilai minimum dan maksimum Z score kurang dari \pm 3 (Ferdinand 2002 dalam Pamungkas 2014).

Setelah melalui tahap ini dilakukan pengujian outlier multivariate. Pengujian secara multivariate outlier dilakukan dengan menggunakan nilai Mahalanobis. Pengujian secara multivariate dilakukan dengan menggunakan software AMOS. Pengamatan multivariate outlier dilakukan pada Mahalanobis distance, Farthest from the centroid.

Standar multivariate outlier dari Mahalanobis adalah menggunakan nilai Chi Square tabel. Jika urutan teratas dari nilai Mahalanobis kurang dari Chi Square tabel maka data tidak terjadi outlier. Dan sebaliknya jika nilai Mahalanobis lebih dari Chi Square tabel maka data terjadi outlier. Chi square tabel ditentukan berdasarkan jumlah variabel yang digunakan dan tingkat kesalahan yang dianjurkan. Menurut Kelloway tingkat kesalahan yang dianjurkan adalah 0,001. Berdasarkan tabel nilai Chi square pada 0,001 dan pada jumlah variable 3 adalah 16,42. Pada pengujian tahap awal outlier multivariate diperoleh nilai Mahalanobis yang sesuai standar.

\section{Uji Normalitas}

Uji normalitas yang harus dipenuhi adalah normalitas univariate dan multivariat. Uji normalitas menggunakan skewness (kemencengan) dan kurtosis (keruncingan). Data dikatakan berdistribusi normal jika mempunyai nilai CR skewness dan kurtosis berada pada kisaran $\pm 2,58$ baik secara univariate dan multivariate. Pengujian path analysis menurut Riduwan dan Kuncoro (2008) haruslah memenuhi persyaratan multivariate normal. Dikatakan memenuhi asumsi multivariate normal jika nilai $C R$ multivariate kurang dari 2,58, pada penelitian ini nilai CR sebesar 1,240. Sedangkan pada pengujian multivariate telah memenuhi syarat karena diperoleh nilai 2.479 yang lebih rendah dari $\pm 2,58$. Dari hasil pengujian ini maka data penelitian memenuhi syarat uji normalitas.

\section{Pengujian Hipotesis}

Parameter ada tidaknya pengaruh secara parsial dapat diketahui berdasarkan nilai CR (Critical Rasio). Untuk menentukan ada tidaknya pengaruh 
variabel eksogen terhadap endogen dan endogen terhadap endogen, digunakan ketentuan melihat dari level of significant $\alpha=0,05$. Jika nilai signifikansi $\leq 0,05$ maka ada pengaruh variabel eksogen terhadap endogen ataupun endogen terhadap endogen. Dan sebaliknya jika nilai signifikansi $>0,05$ maka tidak ada pengaruh variabel eksogen terhadap endogen ataupun endogen terhadap endogen. Hasil selengkapnya uji hipotesis dapat dilihat pada tabel dibawah ini :

Tabel 1.

Hasil Pengujian Hipotesis Pengaruh Langsung

\begin{tabular}{|l|l|l|l|l|}
\hline \multicolumn{2}{|l|}{ Variabel } & $\begin{array}{l}\text { CR } \\
\text { hitung }\end{array}$ & $\begin{array}{l}\text { Tingkat } \\
\text { Signifikan }\end{array}$ \\
\hline $\begin{array}{l}\text { Kualitas } \\
\text { jasa } \\
\text { perspektif } \\
\text { Islam }\end{array}$ & $\rightarrow$ & $\begin{array}{l}\text { Kepuasan } \\
\text { pelanggan }\end{array}$ & 0,000 & Signifikan \\
\hline $\begin{array}{l}\text { Kualitas } \\
\text { jasa } \\
\text { perspektif } \\
\text { Islam }\end{array}$ & $\rightarrow$ & $\begin{array}{l}\text { Loyalitas } \\
\text { pelanggan }\end{array}$ & 0,172 & $\begin{array}{l}\text { Tidak } \\
\text { signifikan }\end{array}$ \\
\hline $\begin{array}{l}\text { Kepuasan } \\
\text { pelanggan }\end{array}$ & $\rightarrow$ & $\begin{array}{l}\text { Loyalitas } \\
\text { pelanggan }\end{array}$ & 0,000 & Signifikan \\
\hline
\end{tabular}

Sumber: Hasil penelitian 2015

Berikut adalah penjelasan hasil pengujian hipotesis pengaruh langsung, yakni:

1. Pengujian Hipotesis Pertama (Pengaruh Kualitas Jasa Perspektif Islam Terhadap Kepuasan Pelanggan). Pengujian dengan menggunakan nilai $C R$ diperoleh nilai 5,718 dengan tingkat signifikansi 0,000. Nilai signifikansi ini kurang dari 0,05. Sehingga hipotesis pertama yang menyatakan bahwa terdapat pengaruh kualitas jasa perspektif Islam terhadap kepuasan pelanggan diterima kebenarannya.

2. Pengujian Hipotesis Kedua (Pengaruh Kualitas Jasa Perspektif Islam Terhadap
Loyalitas Pelanggan). Pengujian dengan menggunakan nilai $C R$ diperoleh nilai 1,367 dengan tingkat tidak signifikansi 0,172 . Nilai tidak signifikansi ini lebih dari 0,05 . Sehingga hipotesis kedua yang menyatakan bahwa terdapat pengaruh kualitas jasa perspektif Islam terhadap loyalitas pelanggan ditolak kebenarannya.

3. Pengujian Hipotesis Ketiga (Pengaruh Kepuasan Pelanggan Terhadap Loyalitas Pelanggan). Pengujian dengan menggunakan nilai $\mathrm{CR}$ diperoleh nilai 5,587 dengan tingkat signifikansi 0,000. Nilai signifikansi ini kurang dari 0,05. Sehingga hipotesis ketiga yang menyatakan bahwa terdapat pengaruh kepuasan pelanggan terhadap loyalitas pelanggan diterima kebenarannya.

\section{Koefisien Jalur Tidak Langsung}

Meskipun pada penelitian ini pengujian path analysis disamping menguji pengaruh langsung, juga pengaruh tidak langsung. Gambar pengaruh tidak langsung dari kualitas jasa perspektif Islam terhadap loyalitas pelanggan melalui kepuasan pelanggan adalah pada halaman berikutnya :

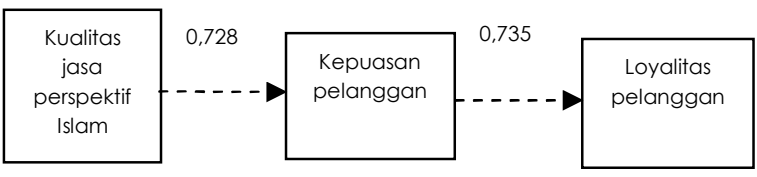

Gambar 2.

Koefisien Jalur Tidak Langsung Gambar menunjukkan bahwa koefisien jalur tidak langsung dari kualitas jasa perspektif Islam terhadap loyalitas melalui kepuasan pelanggan merupakan perkalian dari koefisien jalur langsung dari 
kualitas jasa perspektif Islam terhadap kepuasan pelanggan yaitu 0,728 dan kepuasan pelanggan terhadap loyalitas pelanggan dengan nilai 0,735 . Sehingga nilai koefisien tidak langsung adalah 0,728 $\times 0,735=0,535$.

\section{Pengaruh Kualitas Jasa Perspektif Islam terhadap Kepuasan Pelanggan}

Hasil penelitian menunjukkan bahwa kualitas jasa perspektif Islam berpengaruh signifikan terhadap kepuasan pelanggan hotel Grand Kalimas dengan nilai CR 5,718 dan nilai signifikasi 0,000 . Tingkat signifikansi ini lebih kecil dari 0,05 maka hal ini menunjukkan bahwa hipotesis pertama dapat diterima. Hasil penelitian yang dilakukan Othman dan Owen (2001) menyatakan bahwa kualitas jasa perspektif Islam merupakan faktor dalam membentuk kepuasan pelanggan.

Hasil pengujian hipotesis pertama ini sesuai dengan pernyataan Tjiptono (2001: 259) bahwa kualitas jasa berfokus pada upaya pemenuhan kebutuhan dan keinginan pelanggan, serta ketepatan penyampaiannya untuk mengimbangi harapan pelanggan. Hal ini mendukung indikator variabel kepuasan pelanggan yang kedua yaitu pelayanan hotel Grand Kalimas sesuai dengan harapan pelanggan. Penelitian ini mendukung penelitian Saleem dan Raja (2014), yang menyatakan bahwa pemberian kualitas jasa yang tinggi akan meningkatkan kepuasan pelanggan. Saleem dan Raja (2014) menyebutkan bahwa pelayanan yang lebih baik dalam kualitas jasa di hotel akan menciptakan kepuasan pada pelanggan.

Penelitian ini menunjukkan bahwa dengan penyediaan layanan hotel Grand Kalimas yang sesuai dengan syariah Islam maka akan mempengaruhi kepuasan pelanggan hotel Grand Kalimas. Adanya pengaruh kualitas jasa perspektif Islam terlihat dari jawaban responden yang memiliki skor tinggi pada indikator ketiga yaitu, hotel Grand Kalimas menyediakan makanan dan minuman yang halal akan meningkatkan kepuasan pelanggan hotel Grand Kalimas. Hasil ini diperkuat dengan hasil penelitian Hayati (2014) bahwa pelanggan merasa aman saat mengonsumsi makanan dan minuman yang disediakan hotel karena pelanggan mendapatkan jaminan makanan dan minuman yang halal dari pihak hotel. Sesuai dengan firman Allah SWT dalam surat Al-Baqarah [2] ayat 173.

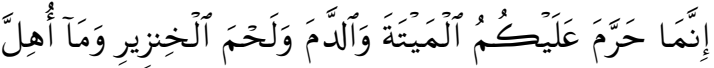

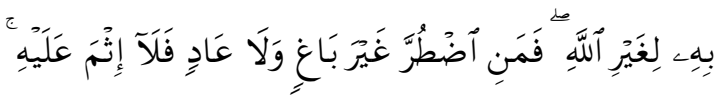

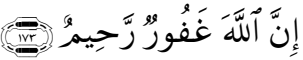

Innamā harrama 'alaikumul maitata waddama walahmal khinzīri wamā uhilla bihī ligairillāh(i), famaniḍ țura gaira bāgiuwalā 'ādinfalā iśma'alaih(i), innallāha gafürurrahīm(un).

"Sesungguhnya Dia hanya mengharamkan atasmu bangkai, darah, daging babi, dan (daging) hewan yang disembelih dengan (menyebut nama) selain Allah. Tetapi barang siapa terpaksa (memakannya), bukan karena menginginkannya dan tidak (pula) melampaui batas, maka tidak ada dosa baginya. Sungguh, Allah Maha Pengampun, Maha Penyanyang". (Departemen Agama Rl, 2010) 
Meskipun kualitas jasa perspektif Islam berpengaruh terhadap kepuasan pelanggan, namun masih terdapat indikator yang nilainya rendah. Indikator ke-14, yaitu karyawan hotel Grand Kalimas (front-desk) tidak melakukan kesalahan dalam melakukan verifikasi reservasi. Sebagai masukan untuk hotel Grand Kalimas, hendaknya karyawan hotel Grand Kalimas (front-desk) selalu mengonfirmasi reservasi dan mencatat setiap reservasi dari pelanggan untuk mengurangi kesalahan.

Selanjutnya, meskipun kualitas jasa perspektif Islam berpengaruh terhadap kepuasan pelanggan, namun masih terdapat indikator dalam kepuasan pelanggan yang nilainya rendah. Indikator tersebut adalah indikator pertama (pelanggan hotel Grand Kalimas memiliki rasa syukur terdapat hotel Grand Kalimas di Surabaya), berdasarkan pertanyaan terbuka, sebagian responden menyatakan bahwa mereka memiliki banyak pilihan terhadap hotel di daerah Ampel yang memberikan nuansa syariah walaupun belum memiliki sertifikat MUI. Oleh karena itu, hendaknya hotel Grand Kalimas memberikan inovasi dalam kualitas jasa perspektif Islam, yaitu menyediakan program berupa paket wisata syariah di kawasan Surabaya.

\section{Pengaruh Kualitas Jasa Perspektif Islam} terhadap Loyalitas Pelanggan

Hasil penelitian menunjukkan bahwa kualitas jasa perspektif Islam berpengaruh tidak signifikan terhadap loyalitas pelanggan hotel Grand Kalimas dengan nilai CR 1,367 dan nilai signifikansi 0,175 . Tingkat signifikansi ini lebih besar dari 0,05 maka hal ini menunjukkan bahwa hipotesis kedua ditolak. Hasil penelitian ini tidak sesuai dengan penelitian Sawitri dkk., (2013) yang menyatakan bahwa ketika pelanggan mendapatkan kualitas jasa yang baik pada saat pertama kali mendapatkan pelayanan dari penyedia jasa, maka mereka akan datang kembali dan mengharapkan pelayanan yang lebih baik lagi pada transaksi berikutnya.

Hasil pengujian hipotesis yang kedua ini tidak sesuai dengan hasil penelitian yang dilakukan Saleem dan Raja (2014) bahwa kualitas jasa berpengaruh terhadap loyalitas pelanggan pada bidang hotel, serta penelitian ini juga tidak sesuai dengan hasil penelitian Kuntjoro (2009) bahwa kualitas jasa yang menggunakan nilai-nilai Islam berpengaruh signifikan terhadap loyalitas pelanggan. Namun, hasil penelitian ini didukung dari hasil penelitian Caruana (2002) bahwa kualitas jasa tidak berpengaruh signifikan terhadap loyalitas pelanggan. Caruana (2002) menyatakan bahwa loyalitas pelanggan dibentuk dari kualitas jasa dan kepuasan pelanggan, bukan hanya dibentuk dari kualitas jasa. Selanjutnya Aryani dan Rosinta (2010) menyatakan bahwa pengaruh yang dihasilkan oleh kualitas jasa dan loyalitas pelanggan tidak signifikan.

Penelitian ini menunjukkan bahwa dari jawaban responden berdasarkan pertanyaan terbuka, sebagian responden menyatakan bahwa ketika mereka 
berkunjung kembali ke Surabaya, belum tentu mereka menginap di hotel Grand Kalimas (indikator ke empat dalam variabel loyalitas pelanggan). Hal tersebut disebabkan responden menyesuaikan daerah tujuan. Hal ini sesuai dengan hasil penelitian Aryani dan Rosinta (2010) bahwa kualitas jasa yang tinggi tidak menjamin pelanggan akan loyal, karena kualitas jasa memiliki pengaruh yang sangat lemah terhadap penciptaan loyalitas pelanggan. Adapun penyebab pengaruh yang sangat lemah dari kualitas jasa dapat dianalisis karena ada faktorfaktor lain (diluar faktor kualitas jasa) yang memberikan pengaruh yang lebih kuat dalam menciptakan loyalitas dibandingkan dengan faktor kualitas jasa.

Selanjutnya, rendahnya indikator ketiga dalam variabel loyalitas pelanggan yaitu ketika hotel Grand Kalimas mengalami kenaikan harga, pelanggan akan tetap menginap di hotel Grand Kalimas. Hal ini karena responden memiliki rasa khawatir karena jika nanti mereka menginap kembali di hotel Grand Kalimas pada saat terjadi kenaikan harga tidak diimbangi dengan kualitas jasa yang baik, serta responden memiliki banyak pilihan terhadap hotel-hotel lain yang memiliki harga dibawah harga hotel Grand Kalimas. Hal tersebut dapat menjadi masukan bagi hotel Grand Kalimas ketika berniat menaikkan harga maka hotel juga harus meningkatkan kualitas jasa sehingga tidak ditinggalkan oleh pelanggan. Manajemen hotel Grand Kalimas dapat menerapkan strategi harga seperti harga promosi dan harga paket. Mengingat sebagian responden adalah pelanggan yang telah beberapa kali menginap di hotel Grand Kalimas, serta pada bulanbulan tertentu terdapat acara di Masjid Sunan Ampel, seperti haul yang mengharuskan jamaah yang datang dari luar kota harus menginap. Sehingga hal tersebut dapat meningkatkan premium purchase pada pelanggan. Hal ini menggambarkan bahwa pelanggan tidak mau menghambur-hamburkan uang untuk hal yang menurut mereka tidak bermanfaat, sesuai dengan firman Allah SWT dalam surat Al-Israa' [17] ayat 26:

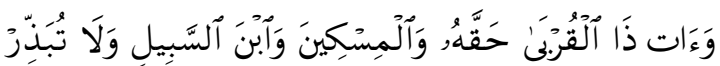

$$
\text { تَبَذِيرًا }
$$

Wa'āti żalqurbā haqqahū walmiskīna wabnassabili walā tubażżir tabżìr(un).

"Dan berikanlah kepada keluargakeluarga yang dekat akan haknya, kepada orang miskin dan orang yang dalam perjalanan dan janganlah kamu menghambur-hamburkan (hartamu) secara boros" (Departemen Agama Rl, 2010)

Selanjutnya, rendahnya indikator ke13 pada variabel kualitas jasa perspektif Islam, yaitu setiap berinteraksi dengan tamu, karyawan hotel Grand Kalimas memanggil dengan nama tamu. Mengingat bahwa mayoritas pelanggan hotel Grand Kalimas berusia lebih dari 50 tahun. Berdasarkan hal tersebut, ketika karyawan hotel Grand Kalimas memanggil tamu hotel dengan nama, maka pelanggan hotel akan merasakan kenyamanan dan perhatian secara psikologis, sehingga dapat memberikan 
persepsi yang baik terhadap pelanggan. Sebaiknya, karyawan hotel memberikan perhatian (empathy) yang lebih terhadap pelanggannya. Indikator rendah juga terlihat pada indikator ke-10 pada variabel kualitas jasa perspektif Islam, yaitu mushalla di hotel Grand Kalimas bersih, tidak lembab, dan mukena yang bersih. Sebagian responden menyatakan bahwa mereka tidak pernah atau jarang menggunakan mushalla yang ada di hotel Grand Kalimas, karena mushalla tidak terletak di area yang mudah dijangkau oleh tamu. Hal ini didukung oleh rendahnya indikator keenam pada variabel loyalitas pelanggan, yaitu pelanggan memberitahu kepada orang lain tentang keuntungan menginap dengan fasilitas di hotel Grand Kalimas. Responden merasa bahwa mereka belum menggunakan seluruh fasilitas yang ada di hotel Grand Kalimas, seperti mushalla. Sehingga sikap loyal responden atas kualitas jasa perspektif Islam pada hotel Grand Kalimas tidak langsung dirasakan oleh responden.

\section{Pengaruh Kepuasan Pelanggan terhadap Loyalitas Pelanggan}

Hasil penelitian menunjukkan bahwa kepuasan pelanggan berpengaruh signifikan terhadap loyalitas pelanggan hotel Grand Kalimas dengan nilai CR 5,587 dan nilai signifikansi 0,000 . Tingkat signifikansi ini lebih kecil dari 0,05 maka hal ini menunjukkan bahwa hipotesis ketiga dapat diterima. Hal ini sesuai dengan pernyataan Fornell (1999 dalam Aryani dan Rosinta, 2010) kepuasan pelanggan merupakan kunci dalam menciptakan loyalitas pelanggan. Kepuasan atau ketidakpuasan pelanggan pada pelayanan yang mereka dapatkan akan berdampak pada perilaku pembelian selanjutnya.

Hasil pengujian hipotesis ketiga ini sesuai dengan hasil penelitian Kandampully dan Suhartanto (2000) yang menyatakan bahwa kepuasan pelanggan memiliki pengaruh yang signifikan terhadap loyalitas pelanggan. Serta penelitian Carvana (2002) yang menyatakan bahwa kepuasan pelanggan memiliki hubungan langsung terhadap loyalitas pelanggan. Selain itu Saleem dan Raja (2014) menyatakan bahwa terdapat hubungan yang positif antara kepuasan pelanggan dan loyalitas pelanggan.

Penelitian ini menunjukkan bahwa dari jawaban responden berdasarkan pertanyaan terbuka, sebagian responden menyatakan bahwa mereka secara keseluruhan merasa puas dengan pengalaman menginap di hotel Grand Kalimas (indikator kelima dalam variabel kepuasan pelanggan), sehingga responden tersebut kembali menginap di hotel Grand Kalimas, serta mereka menyatakan bahwa akan menceritakan pengalaman mereka kepada orang lain (indikator ketujuh dalam variabel loyalitas pelanggan).

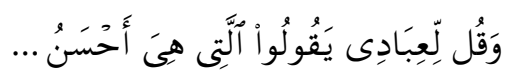

Waqulli'ibādī yaqulullatī hiya 'ahsanu... 
Dan katakanlah kepada hamha-hambaKu: "Hendaklah mereka mengucapkan perkataan yang lebih baik (benar)..." (Departemen Agama Rl, 2010) Meskipun kepuasan pelanggan berpengaruh terhadap loyalitas pelanggan, namun masih terdapat indikator dalam kepuasan pelanggan yang nilainya rendah. Indikator tersebut adalah indikator ketiga (pelanggan merasa pelayanan hotel Grand Kalimas sesuai dengan yang dijanjikan) dan indikator keempat (manfaat yang pelanggan rasakan saat menginap di hotel Grand Kalimas sesuai dengan biaya yang pelanggan keluarkan), berdasarkan pertanyaan terbuka, sebagian responden menyatakan bahwa fasilitas yang mereka dapatkan belum sepenuhnya sesuai dengan biaya yang mereka kelvarkan, misalnya keset handuk di kamar mandi tidak tersedia, tisu di kamar mandi tidak tersedia, stop contact di kamar ada yang tidak berfungsi dengan baik, mukena tidak tersedia di dalam kamar. Hal ini dapat menjadi masukan bagi hotel Grand Kalimas untuk melengkapi fasilitas, seperti keset handuk, tisu, mukena, dan stop contact.

\section{SIMPULAN}

Kesimpulan yang dapat diambil dari hasil penelitian dengan menggunakan path analysis yang sudah dilakukan adalah sebagai berikut :

1. Kualitas jasa perspektif Islam berpengaruh secara signifikan terhadap kepuasan pelanggan.
2. Kualitas jasa perspektif Islam tidak berpengaruh secara signifikan terhadap loyalitas pelanggan.

3. Kepuasan pelanggan berpengaruh secara signifikan terhadap loyalitas pelanggan.

4. Kualitas jasa perspektif Islam tidak berpengaruh secara langsung terhadap loyalitas pelanggan.

\section{DAFTAR PUSTAKA}

Anshori, Muslich dan Sri Iswati. 2009. Metodologi Penelitian Kuantitatif (Bahan Ajar). Surabaya: Airlangga University Press

Caruana, Albert. 2002. Service Loyalty: The Effect of Service Quality and The Mediating Role of Customer Satisfaction. European Journal of Marketing. XXXVI (7): 81 1-828

Departemen Agama Republik Indonesia. 2010. Al-Qur'an dan Terjemahannya: Special for Women. Bandung: Syaamil Al-Qur'an

Gilbert, G. Ronald, Cleopatra Veloutsou, Mark M. H. Goode, and Luiz Moutinho. 2004. Measuring Customer Satisfaction in the Fast Food Industry: A Crossnational Approach. Journal of Service Marketing, XVIII (5): 371-383

Gunara, Thorik dan Utus Hardiono Sudibyo. 2007. Marketing Muhammad: Strategi Andal dan Jitu Praktik Bisnis Nabi Muhammad SAW. Bandung: PT Karya Kita

Hayati, Asfarina. 2014. Faktor-faktor Yang Mempengaruhi Konsumen Muslim Memilih Hotel Syariah Grand Kalimas Surabaya. Skripsi tidak diterbitkan. 
Surabaya: Fakultas Ekonomi dan Bisnis Universitas Airlangga

Jafari, Jafar and Noel Scott. 2013. Muslim

World and Its Tourism. Journal of Tourism Research 44: 1-19

Jawa Pos. 2015, 16 Januari.

Perkembangan Hotel Syariah Stagnan. hlm. 6

Kandampully, Jay and Dwi Suhartanto. 2000. Customer Loyalty in The Hotel Industry: Ccustomer Satisfaction And Image. International Journal of Contemporary Hospitality. XII (6): 346351

Kholidah, Himmatul. 2014. Dampak Ekonomi Wisata Syariah Terhadap Pendapatan Pedagang di Kawasan Wisata Religi Masjid Sunan Ampel Surabaya. Skripsi tidak diterbitkan. Surabaya: Fakultas Ekonomi dan Bisnis Universitas Airlangga

Kotler, Philip and Kevin Lane Keller. 2009. Manajemen Pemasaran. Edisi 13 Jilid 1. Jakarta: Erlangga

Lovelock, Christopher H. \& Laurent K. Wright. 2007. Manajemen Pemasaran Jasa cetakan ke-2. Indeks

Masyhuri, Dr Ir MP, dan M. Zainuddin, Drs MA. 2009. Metodologi Penelitian: Pendekatan Praktis dan Aplikatif. Bandung: Rafika Aditama

Othman, Abdul Qawi dan Lynn Owen. 2001. Adopting and Measuring Customer Service Quality (SQ) in Islamic Banks: a case Study in Kuwait Finance House. Internasional Journal of Islamic Financial Service, III (1).
Pamungkas, Astria Primadhani. 2014. Pengaruh Pemasaran Internal Terhadap Komitmen Kerja Islam dan Kinerja Perawat Rumah Sakit Islam Jemursari Surabaya. Skripsi tidak diterbitkan. Surabaya: Fakultas Ekonomi dan Bisnis Universitas Airlangga

Parasuraman, A., Valerie A. Zeithaml, and Leonard L. Berry. 1985. A Conceptual Model of Service Quality and Its Implications for Future Research. Journal of Marketing (pre-1986); Fall 1985; 49, 000004; ABI/INFORM Global pg.41

Rahmawati, Putri Eryka. 2014. Pengaruh Kualitas Jasa Dalam Perspektif Islam Terhadap Kepuasan Konsumen Muslim dan Niat Berpindah Yang Dimoderasi Oleh Tingkat Pengetahuan Agama pada Nasabah Bank Muamalat di Surabaya. Skripsi tidak diterbitkan. Surabaya: Fakultas Ekonomi dan Bisnis Universitas Airlangga

Ratnasari, Ririn Tri. Adistiar Prayoga, and Nisful Laila. 2012. Measuring Customer Service Quality Based on Fatanah Implementation. Proceedings of 2 nd Global Islamic Marketing Conference (GIMC). Abu Dhabi

dan Mastuti Aksa. 2011 . Teori dan Kasus Manajemen Pemasaran Jasa. Bandung: Ghalia Indonesia

Rehman, Asma Abdul. 2012. Customer Satisfaction and Service Quality in Islamic Banking: A Comparative Study in Pakistan, United Arab Emirates and United Kingdom. Journal Qualitative 
Research in Financial Markets, IV (2/3): 165-175

Riduwan, Drs, MBA, dan Engkos Achmad Kuncoro, Dr, SE, MM. 2008. Cara Menggunakan dan Memaknai Analisis Jalur (Path Analysis). Bandung: Alfabeta

Sabri, Fahruddin Ali. 2010. Perkembangan Hotel Syari'ah di Indonesia: Mengonsep Pariwisata Islam. Karsa XVIII (2): 114-122

Saleem, Hamad and Naintara Sarfraz Raja. 2014. The Impact of Service Quality on Customer Seaticfaction, Customer Loyalty and Brand Image: Evidence From Hotel Industry of Pakistan. Journal of Scientific Research, XIX (5): 706-711

Sanusi, Anwar, Prof, DR, SE, MSi. 2013. Metodologi Penelitian Bisnis. Cetakan Ketiga. Jakarta: Salemba Empat

Sawitri, Ni Putu, Ni Nyoman Kerti Yasa, dan Abdullah Jawas. 2013. Pengaruh Kualitas Layanan Terhadap Kepuasan dan Loyalitas Pelanggan Tegal Sari Accommodation Di Ubud. Jurnal Manajemen, Strategi Bisnis, dan Kewirausahaan. VII (1): 40-47

Solimun. 2002. Sructural Equation Modeling Lisrel dan Amos. Malang: Fakultas MIPA Universitas Brawijaya

Sugiyono. 2011. Metode Penelitian Kuantitatif, kualitatif dan R\&D. Bandung: Alfabeta

Tjiptono, Fandy. 2000. Manajemen Jasa. Yogyakarta: Penerbit Andi 2005. Pemasaran Jasa. Malang:

Bayumedia Publishing
Zulfa, Moch. 2010. Pengaruh Kualitas Pelayanan Islami dan Citra Terhadap Kepuasan dan Loyalitas Pasien Rumah Sakit Islam Jawa Tengah. Disertasi tidak diterbitkan. Surabaya: Program Pasca Sarjana Universitas Airlangga

Indonesiatravel.com (diakses 7 Desember 2014)

Kabarbisnis.com. (diakses 7 Desember 2014)

Wartametropis.com (diakses 1 Januari 2015) 